\title{
Critical Inhaler Handling Error Is an Independent Risk Factor for Frequent Exacerbations of Chronic Obstructive Pulmonary Disease: Interim Results of a Single Center Prospective Study
}

This article was published in the following Dove Press journal:

International Journal of Chronic Obstructive Pulmonary Disease

June Hong Ahn (D)

Jin Hong Chung (D

Kyeong-Cheol Shin (D)

Eun Young Choi

Hyun Jung Jin

Mi Suk Lee

Mi Jeong Nam

Kwan Ho Lee

Division of Pulmonology and Allergy, Department of Internal Medicine, Yeungnam University Medical Center, College of Medicine, Yeungnam University, Daegu, South Korea
Correspondence: Kwan Ho Lee Division of Pulmonology and Allergy, Department of Internal Medicine, Yeungnam University Medical Center, 170 Hyunchung-Ro, Nam-Gu, Daegu 424I5, South Korea

Email ghlee@med.yu.ac.kr
Objective: Chronic obstructive pulmonary disease (COPD) acute exacerbations are significant causes of morbidity and mortality. "Frequent exacerbator" phenotypes are considered a distinct subgroup and this phenotype has a negative effect on lung function, quality of life, activity, hospital admission, and mortality. We assess inhaler handling technique and adherence, and evaluate risk factors associated with frequent exacerbations in COPD patients.

Methods: This study was a cross-sectional, case-control study. We prospectively enrolled 189 COPD patients from Yeungnam University Hospital from January 2018 to November 2018. Subjects were tested regarding their inhaler technique in face-to-face interviews with an advanced practice nurse of inhaler upon study entry. Frequency of moderate to severe COPD exacerbations were reviewed via electronic medical records during 12 months prior to study entry. Frequent exacerbations were defined as $\geq 2$ moderate to severe exacerbations in the prior 12 months. Multivariate logistic regression was performed to identify risk factors for frequent exacerbations. Results: Among 189 COPD patients, 50 (26.5\%) were frequent exacerbators. Based on univariate analyses, body mass index (BMI) $<25 \mathrm{~kg} / \mathrm{m}^{2}$, lower forced expiratory volume in $1 \mathrm{~s}\left(\mathrm{FEV}_{1}\right)$, higher mMRC, lower feeling of satisfaction with the inhaler, and any critical errors were potential risk factors for frequent exacerbations. Multivariate logistic regression analyses revealed that $\mathrm{BMI}<25 \mathrm{~kg} / \mathrm{m}^{2}$ (OR, 2.855, 95\% CI, 1.247-6.534; $\mathrm{p}=0.013$ ), higher mMRC (OR, 1.625, 95\% CI, 1.072-2.463; $\mathrm{p}=0.022)$, and any critical error $(\mathrm{OR}, 2.020,95 \%$ CI, 1.021-3.999; $\mathrm{p}=0.044)$ were risk factors.

Conclusion: Any critical error, BMI $<25 \mathrm{~kg} / \mathrm{m}^{2}$ and high $\mathrm{mMRC}$ are independent risk factors for frequent exacerbations in COPD patients. Careful monitoring and education around inhaler devices, particularly in frequent exacerbators, are important components of COPD treatment.

Keywords: COPD, inhalation therapy, drug use error, disease exacerbation

\section{Introduction}

Chronic obstructive pulmonary disease (COPD) is a chronic airway disease that has increased in prevalence worldwide. ${ }^{1,2}$ Exacerbation of COPD is defined as an acute worsening of respiratory symptoms that requires additional therapy. Some COPD patients frequently experience acute exacerbations and are now categorized as a distinct phenotype, the "frequent exacerbators." This phenotype has a negative effect on lung function, quality of life, activity, hospital admission, and mortality. ${ }^{3}$ 
The use of inhalers is the cornerstone of treatment for COPD management. Correct use of the inhaler improves lung function, quality of life, and prevents exacerbation of COPD. ${ }^{4-7}$ However, inhalation technique and adherence in COPD patients has been reported to be unsatisfactory in previous reports. ${ }^{8-10}$ Improper use of inhalers can interfere with effective drug delivery to the airways, leading to poor disease control. Many studies have explored the effects of increased inhaler error frequency and the association with poor disease outcomes in asthma patients; ${ }^{11,12}$ however, few studies have explored the association between inhaler mishandling and poor disease outcomes in COPD patients. ${ }^{9,13,14}$ One study has explored the potential impact of inhaler device mishandling on COPD exacerbation. ${ }^{9}$ Other study revealed patients with suboptimal peak inspiratory flow had increased risk of readmission after hospitalization for acute exacerbation of COPD. ${ }^{14}$

This study evaluated the frequency of critical errors for various inhaler devices and demonstrated an association between inhaler handling error and frequent exacerbations.

\section{Methods}

\section{Study Design and Subjects}

This was a prospective cross-sectional study conducted in the outpatient pulmonology clinic at the Regional Center for Respiratory Disease, Yeungnam University Hospital, a tertiary university hospital in Daegu, South Korea, from January 2018 to November 2018. Patients aged over 40 years old who were diagnosed with COPD and had been using any inhaler device longer than 1 year prior to the study were recruited. We assessed the commonly used inhaler devices available in South Korea, namely, Turbuhaler ${ }^{\circledR}$, Breezhaler $^{\circledR}$, Ellipta ${ }^{\circledR}$, Diskus ${ }^{\circledR}$, Genuair ${ }^{\circledR}$, Respimat $^{\circledR}$, and pressurized metered dose inhaler (pMDI). We excluded patients using other inhaler devices, those with advanced malignant cancer, and pregnant women. This study was conducted in accordance with the Declaration of Helsinki and was reviewed and approved by the institutional review board of our hospital (YUH IRB 2017-09-012). Written informed consent was obtained from all patients.

\section{Data Collection and Definitions}

The subjects were assessed regarding their inhaler handling technique and adherence in face-to-face interviews with an advanced practice nurse of inhaler education (MJN). The nurse was previously educated and trained by COPD specialists and had 3 years of experience in educating on the use of inhaler devices in COPD patients at Yeungnam University Hospital at the time of the study.

Critical errors were defined as those affecting the lung deposition of inhaled drug, resulting in little or no drug deposition. ${ }^{15}$ In multiple device users, if any of the devices have a critical error, it is defined as critical error. Because there is no standardized checklist of inhaler yet, we made our own checklist based on the previous literature. ${ }^{15}$ These errors included failure to open the device correctly, failure to seal the lips around the mouthpiece during inhalation, not inhaling forcefully or deeply enough when using a dry powder inhaler (DPI), and the following for each specific device:

1. Turbuhaler ${ }^{\circledR}:$ Failure to hold the device upright while priming, failure to prime (rotating grip anticlockwise and then back until the "click" sound is heard)

2. Breezhaler ${ }^{\circledR}$ : Failure to place a capsule in the chamber, failure to close the mouthpiece until the "click" sound is heard, inadequately pressing the buttons to pierce a capsule, and capsule removal without checking for powder residue at the end of inhalation

3. Ellipta ${ }^{\circledR}:$ The above mentioned DPI's critical error (failure to open the device correctly, failure to seal the lips around the mouthpiece during inhalation, not inhaling forcefully or deeply)

4. Diskus ${ }^{\circledR}$ : Failure to push the lever back fully until the "click" sound is heard

5. Genuair $^{\circledR}$ : Failure to hold the inhaler horizontally with the green button facing upwards for priming

6. Respimat $^{\circledR}$ : Failure to twist the base a half turn, lack of synchronization between actuation and inhalation, not breathing slowly and deeply

7. pMDI $^{\circledR}$ : Not shaking the inhaler well (only in suspension formulation), not keeping the inhaler upright, lack of synchronization between actuation and inhalation, not breathing slowly and deeply

Adherence records were assessed as self-reporting of the patient and classified as good, partial, and poor. Records were considered good if they had been taking the full daily inhaler requirement (frequency and dose) as prescribed, partial if they had been taking more or less than the daily inhaler requirement (frequency and dose) as prescribed, and poor if they had been taking the inhaler as needed during symptom aggravation or not at all. ${ }^{16}$

COPD exacerbations in the previous year were assessed via electronic medical records. COPD exacerbation was defined as an acute worsening of respiratory symptoms 
resulting in additional therapy. Moderate exacerbation was defined as an exacerbation requiring treatment with systemic corticosteroids and/or antibiotics. Severe exacerbation was defined if the patient visited the emergency room or required hospitalization because of an exacerbation. Frequent exacerbator was defined as any patient who had two or more treated exacerbations in the previous year. ${ }^{17,18}$

All patients had spirometry records at study enrollment performed within the past 3 months. A general questionnaire (age, sex, body mass index, total number of inhalations per day, smoking status, duration of COPD, previous education for handling inhaler, previous education for COPD, level of education, and use of multiple devices), the modified Medical Research Council, ${ }^{19}$ COPD assessment test $(\mathrm{CAT}),{ }^{20}$ Mini-Mental State Examination (MMSE), ${ }^{21}$ EuroQol-5D (EQ-5D), ${ }^{22}$ patient health questionnaire (PHQ9), ${ }^{23}$ and feeling of satisfaction with the inhaler questionnaire $\left(\right.$ FSI-10) ${ }^{24}$ were given to all patients at the enrollment visit.

\section{Statistical Analyses}

Continuous variables are expressed as means \pm standard deviation (SDs) and were compared using the Student's $t$-test or the Mann-Whitney $U$-test. Categorical variables were compared using the chi-square test or Fisher's exact test. When continuous variables were converted into categorical variables, cut-off values were determined using receiver operating characteristic curves. Multivariate logistic regression analyses were performed to identify independent risk factors for frequent exacerbators using variables with a p-value $<0.1$ in univariate analyses, as measured using odds ratios (ORs) with $95 \%$ confidence intervals (CIs). Age and sex also were included in multivariate logistic regression analyses. In all analyses, $\mathrm{p}<0.05$ based on two-tailed tests was considered to indicate statistical significance. All statistical procedures were performed using SPSS software (ver. 24.0; SPSS Inc., Chicago, IL).

Prospective power calculations indicated that the overall sample size of 140 patients was required to detect $20 \%$ decrease of COPD exacerbation (90\% power, $\alpha=0.05$, effect size $=0.5$ ). To account for dropout rate, we aimed to enroll 180 patients. $^{25}$

\section{Results}

\section{Baseline Characteristics}

The mean age of the patients was 69.9 years and the mean BMI was $23.8 \mathrm{~kg} / \mathrm{m}^{2}$. The majority of COPD patients were male $(93.1 \%)$ and the mean duration of COPD was 4.5 years (Table 1). The mean number of inhalations was 2.3 puffs per day, and 44 (23.3\%) patients were using multiple types of inhaler devices. Most patients had mild to moderate airflow limitations $\left(62.4 \pm 17.8\right.$ predictive $\left.\mathrm{FEV}_{1}\right)$ and more than one fourth were frequent exacerbators.

Table I Baseline Characteristics of COPD Patients

\begin{tabular}{|c|c|}
\hline Variables & $N=189$ \\
\hline Age (years) & $69.9 \pm 7.5$ \\
\hline Male sex, n (\%) & $176(93.1)$ \\
\hline Body Mass Index $\left(\mathrm{kg} / \mathrm{m}^{2}\right)$ & $23.8 \pm 3.4$ \\
\hline \multicolumn{2}{|l|}{ Smoking status } \\
\hline Never smoker & $23(12.2)$ \\
\hline Ex-smoker & $129(68.3)$ \\
\hline Current smoker & $37(19.6)$ \\
\hline Duration of COPD & $4.5 \pm 4.3$ \\
\hline Total number of inhalations per day & $2.3 \pm 1.3$ \\
\hline Previous education for COPD & $180(95.2)$ \\
\hline Previous education for handling the inhaler & $180(95.2)$ \\
\hline \multicolumn{2}{|l|}{ Education level } \\
\hline Lower education ( $\leq 6 y e a r s$ ) & $73(38.6)$ \\
\hline Higher education (>6years) & $116(6 \mid .4)$ \\
\hline Use of multiple devices ( $\geq 2$ devices) & $44(23.3)$ \\
\hline Ratio of $\mathrm{FEV}_{1} / \mathrm{FVC}(\%)$ & $57.2 \pm 13.8$ \\
\hline Percent predicted FEV & $62.4 \pm 17.8$ \\
\hline Percent predicted DLCO $(n=188)$ & $68.6 \pm 20.0$ \\
\hline \multicolumn{2}{|l|}{ GOLD } \\
\hline I, II & $144(76.2)$ \\
\hline III, IV & $45(23.8)$ \\
\hline mMRC score & $1.3 \pm 0.8$ \\
\hline CAT score & $9.8 \pm 5.6$ \\
\hline MMSE $(n=186)$ & $29.4 \pm 1.6$ \\
\hline Moderate exacerbation in the previous I year & $84(44.4)$ \\
\hline Severe exacerbation in the previous I year & $31(16.4)$ \\
\hline Frequent exacerbations in the previous I year & $50(26.5)$ \\
\hline
\end{tabular}

Note: Data are presented as the mean \pm standard deviation (range) or number (percentage).

Abbreviations: COPD, chronic obstructive pulmonary disease; CAT, COPD Assessment Test; DLCO, diffusion capacity for carbon monoxide; $\mathrm{FEV}_{1}$, forced expiratory volume in I s; FVC, force vital capacity; GOLD, Global Initiative for Chronic Obstructive Lung Disease; mMRC, modified Medical Research Council; MMSE, mini-mental state examination. 


\section{Critical Errors for Each Step When Handling Inhaler Devices}

A total of 189 COPD patients using 233 inhaler devices were included for the analyses of critical errors. At least one such error was observed in $42.9 \%$ of patients (81/189). Percentages of errors for each step per inhaler device are presented in Table 2. The majority of errors were observed when using pressurized metered disease inhalers (pMDI) (57.1\%), followed by soft mist inhaler (SMI) $(42.3 \%)$ and DPI (39.1\%). When analyzing by device, the most critical errors were observed in Turbuhaler ${ }^{\circledR}$ users $(n=12,66.7 \%)$, followed by pMDI users $(n=8,57.1 \%)$, Breezhaler ${ }^{\circledR}$ users $(n=21,42.9 \%)$, Genuair ${ }^{\circledR}$ users $(n=6,42.9 \%)$, Respimat ${ }^{\circledR}$ users $(n=44,42.3 \%)$, Ellipta ${ }^{\circledR}$ users $(n=5,19.2 \%)$, and Diskus $^{\circledR}$ users $(n=1,12.5 \%)$. For the Turbuhaler ${ }^{\circledR}$, "failure to prime while holding the device upright" and "not inhaling forcefully or deeply" were the most common critical errors. For the Breezhaler ${ }^{\circledR}$, "not inhaling forcefully or deeply" and "inadequately pressing the buttons to pierce the capsule" were the most common. For the Ellipta ${ }^{\circledR}$, "not inhaling forcefully or deeply" was the most common. For the Diskus ${ }^{\circledR}$, "failure to push the lever back fully" was the most common. For the Genuair ${ }^{\circledR}$, "not inhaling forcefully or deeply" and "failure to hold the inhaler horizontally with the green button facing upwards for priming" were the most common. For the Respimat ${ }^{\circledR}$, "failure to twist the base a half turn," "failure to open the device correctly," and "lack of synchronization between actuation and inhalation" were the most common. For the pMDI, "not breathing slowly and deeply," "lack of synchronization between actuation and inhalation," and "shaking inhaler well with keeping the inhaler upright" were the most common.

\section{Factors Associated with Frequent Exacerbations}

Factors associated with frequent exacerbations are listed in Tables 3 and 4. In univariate analyses, $\mathrm{BMI}<25 \mathrm{~kg} / \mathrm{m}^{2}$ (OR, 2.723, 95\% CI, 1.225-6.054; $\mathrm{p}=0.012$ ), lower $\mathrm{FEV}_{1}$ (OR, 0.983, 95\% CI, 0.965-1.001; $\mathrm{p}=0.069$ ), higher mMRC (OR, 1.574, 95\% CI, 1.063-2.329; $\mathrm{p}=0.023$ ), lower feeling of satisfaction with the inhaler (OR, $0.942,95 \%$ CI, 0.878 1.010; $\mathrm{p}=0.095)$, and any critical error (OR, $2.310,95 \% \mathrm{CI}$, $1.196-4.463 ; \mathrm{p}=0.012$ ) were potential risk factors for frequent exacerbators. Multivariate logistic regression analyses revealed that $\mathrm{BMI}<25 \mathrm{~kg} / \mathrm{m}^{2}$ (OR, 2.855, 95\% CI, $1.247-$ 6.534; $\mathrm{p}=0.013$ ), higher mMRC (OR, 1.625, 95\% CI, 1.0722.463; $\mathrm{p}=0.022)$, and any critical error $(\mathrm{OR}, 2.020,95 \% \mathrm{CI}$, $1.021-3.999 ; \mathrm{p}=0.044$ ) were risk factors for frequent exacerbations in COPD patients. The rate of exacerbations

Table 2 Critical Errors per Inhaler Device

\begin{tabular}{|c|c|c|c|c|c|c|c|}
\hline Critical Steps & $\begin{array}{l}\text { Turbuhaler }^{\circledR} \\
\mathrm{n}=18\end{array}$ & $\begin{array}{l}\text { Breezhaler }^{\circledR} \\
n=49\end{array}$ & $\begin{array}{l}\text { Ellipta }^{\circledR} \\
\mathbf{n}=\mathbf{2 6}\end{array}$ & $\begin{array}{l}\text { Diskus }^{\circledR} \\
\mathrm{n}=\mathbf{8}\end{array}$ & $\begin{array}{l}\text { Genuair }^{\circledR} \\
n=14\end{array}$ & $\begin{array}{l}\text { Respimat }^{\circledR} \\
n=104\end{array}$ & $\begin{array}{l}\text { pMDI } \\
n=14\end{array}$ \\
\hline Twist the base a half turn & NA & NA & NA & NA & NA & $22(2 \mid .2)$ & NA \\
\hline Open the device correctly & $0(0)$ & $0(0)$ & $2(7.7)$ & $0(0)$ & $0(0)$ & $22(2 \mid .2)$ & $0(0)$ \\
\hline Priming with device upright & $9(50.0)$ & NA & NA & NA & NA & NA & NA \\
\hline Push the lever back fully & NA & NA & NA & I (I2.5) & NA & NA & NA \\
\hline Place capsule in the chamber & NA & $0(0)$ & NA & NA & NA & NA & NA \\
\hline Close the mouthpiece & NA & $4(8.2)$ & NA & NA & NA & NA & NA \\
\hline Press buttons to pierce a capsule & NA & II (22.4) & NA & NA & NA & NA & NA \\
\hline $\begin{array}{l}\text { Hold the inhaler horizontally green button } \\
\text { facing upwards for priming }\end{array}$ & NA & NA & NA & NA & $3(21.4)$ & NA & NA \\
\hline Shaking inhaler well & NA & NA & NA & NA & NA & NA & I (7.I) \\
\hline Keeping inhaler upright & NA & NA & NA & NA & NA & NA & $2(14.3)$ \\
\hline Seal lips around mouthpiece during inhalation & $0(0)$ & $0(0)$ & $0(0)$ & $0(0)$ & $0(0)$ & $6(5.8)$ & $0(0)$ \\
\hline Inhale forcefully or deeply & $4(22.2)$ & $13(26.5)$ & $3(\mathrm{II} .5)$ & $0(0)$ & $4(28.6)$ & NA & NA \\
\hline $\begin{array}{l}\text { Synchronization between actuation and } \\
\text { inhalation }\end{array}$ & NA & NA & NA & NA & NA & $22(2 \mid .2)$ & $2(14.3)$ \\
\hline Inhale slowly and deeply & NA & NA & NA & NA & NA & $21(20.2)$ & $3(21.4)$ \\
\hline $\begin{array}{l}\text { Capsule removed with checking for powder } \\
\text { residue }\end{array}$ & NA & $5(10.2)$ & NA & NA & NA & NA & NA \\
\hline Patients performing at least one critical error & $12(66.7)$ & $21(42.9)$ & $5(19.2)$ & I (I2.5) & $6(42.9)$ & $44(42.3)$ & $8(57.1)$ \\
\hline
\end{tabular}

Note: Data are presented as the number (percentage).

Abbreviations: pMDI, pressurized metered-dose inhaler; NA, not applicable to the device. 
Table 3 Clinical Characteristics of Frequent Exacerbators and Infrequent exacerbators

\begin{tabular}{|c|c|c|c|}
\hline & Frequent Exacerbator & Infrequent Exacerbator & P Value \\
\hline Total number & $50(26.5)$ & $139(73.5)$ & \\
\hline Age (years) & $69.6 \pm 8.6$ & $70.0 \pm 7.2$ & 0.756 \\
\hline Male sex, n (\%) & $46(92.0)$ & $130(93.5)$ & 0.747 \\
\hline BMI $\left(\mathrm{kg} / \mathrm{m}^{2}\right)$ & $22.9 \pm 3.1$ & $24.1 \pm 3.4$ & 0.044 \\
\hline $\mathrm{BMI}<25$ & $4 I(82.0)$ & $87(62.6)$ & 0.012 \\
\hline $\mathrm{BMI} \geq 25$ & $9(18.0)$ & $52(37.4)$ & \\
\hline Smoking status & & & 0.426 \\
\hline Never smoker & $8(16.0)$ & $15(10.8)$ & \\
\hline Ex-smoker & $33(66.0)$ & $96(69.1)$ & \\
\hline Current smoker & $9(18.0)$ & $28(20.1)$ & \\
\hline Duration of COPD & $4.7 \pm 3.8$ & $4.4 \pm 4.5$ & 0.636 \\
\hline Total number of inhalations per day & $2.4 \pm 1.6$ & $2.3 \pm 1.2$ & 0.697 \\
\hline Previous education for COPD & $48(96.0)$ & $132(95.0)$ & 1.000 \\
\hline Previous education for handling inhaler & $49(98.0)$ & $|3|(94.2)$ & 0.449 \\
\hline Education level & & & 0.657 \\
\hline Lower education ( $\leq 6$ years) & $55(39.6)$ & $18(36.0)$ & \\
\hline Higher education ( $>6$ years) & $84(60.4)$ & $32(64.0)$ & \\
\hline \multicolumn{4}{|l|}{ Pulmonary functions test } \\
\hline Ratio of $\mathrm{FEV}_{\mathrm{I}} / \mathrm{FVC}(\%)$ & $55.8 \pm 13.7$ & $57.7 \pm 13.8$ & 0.415 \\
\hline Percent predicted FEV & $58.5 \pm 18.9$ & $63.9 \pm 17.2$ & 0.067 \\
\hline Percent predicted DLCO $(n=188)$ & $66.7 \pm 17.9$ & $69.3 \pm 20.8$ & 0.430 \\
\hline GOLD & & & 0.231 \\
\hline I, II & $35(70.0)$ & $109(78.4)$ & \\
\hline III, IV & $15(30.0)$ & $30(21.6)$ & \\
\hline \multicolumn{4}{|l|}{ Outcome by questionnaire } \\
\hline mMRC score & $1.5 \pm 0.9$ & $1.2 \pm 0.8$ & 0.021 \\
\hline CAT score & $10.8 \pm 5.4$ & $9.4 \pm 5.7$ & 0.148 \\
\hline MMSE $(n=186)$ & $29.3 \pm 1.7$ & $29.4 \pm 1.6$ & 0.785 \\
\hline EQ-5D & $0.9 \pm 0.1$ & $0.9 \pm 0.1$ & 0.713 \\
\hline PHQ-9 & $1.2 \pm 2.2$ & $1.2 \pm 2.5$ & 0.931 \\
\hline FSI-10 & $43.7 \pm 5.2$ & $44.9 \pm 4.2$ & 0.128 \\
\hline \multicolumn{4}{|l|}{ Inhaler assessment } \\
\hline Any critical error & $29(58.0)$ & $52(37.4)$ & 0.012 \\
\hline Adherence & & & $0.44 I$ \\
\hline Good & $43(86.0)$ & III (79.9) & \\
\hline Partial & $6(12.0)$ & $26(18.7)$ & \\
\hline Poor & I (2.0) & $2(1.4)$ & \\
\hline
\end{tabular}

Note: Data are presented as the mean \pm standard deviation (range) or number (percentage).

Abbreviations: BMI, body mass index; CAT, COPD Assessment Test; COPD, chronic obstructive pulmonary disease; DLCO, diffusion capacity for carbon monoxide; EQ5D, EuroQol-5D; FEV , forced expiratory volume in I s; FSI-10, feeling of satisfaction with inhaler questionnaire; FVC, force vital capacity; GOLD, Global Initiative for Chronic Obstructive Lung Disease; mMRC, modified Medical Research Council; MMSE, mini-mental state examination; PHQ-9, patient health questionnaire. 
Table 4 Predictors of Frequent Exacerbators in Patients with COPD Based on Logistic Regression Analyses

\begin{tabular}{|c|c|c|c|c|c|c|}
\hline & \multicolumn{3}{|c|}{ Univariate } & \multicolumn{3}{|c|}{ Multivariate } \\
\hline & OR & $95 \% \mathrm{Cl}$ & P Value & OR & $95 \% \mathrm{Cl}$ & P Value \\
\hline Age (years) & 0.993 & $0.952-1.037$ & 0.755 & & & \\
\hline Male sex, n (\%) & 0.796 & $0.234-2.710$ & 0.747 & & & \\
\hline BMI $<25\left(\mathrm{~kg} / \mathrm{m}^{2}\right)$ & 2.723 & $1.225-6.054$ & 0.012 & 2.855 & $1.247-6.534$ & 0.013 \\
\hline Percent predicted FEVI & 0.983 & $0.965-1.001$ & 0.069 & & & \\
\hline mMRC score & 1.574 & $1.063-2.329$ & 0.023 & 1.625 & $1.072-2.463$ & 0.022 \\
\hline FSI-I0 & 0.942 & $0.878-1.010$ & 0.095 & & & \\
\hline Any critical error & 2.310 & I.196-4.463 & 0.012 & 2.020 & $1.021-3.999$ & 0.044 \\
\hline
\end{tabular}

Note: Data are presented as mean \pm standard deviation (range) or number (percentage).

Abbreviations: $\mathrm{BMI}$, body mass index; $\mathrm{Cl}$, confidence interval; $\mathrm{FEV}_{1}$, forced expiratory volume in I s; FSI-I0, feeling of satisfaction with inhaler questionnaire; FVC, force vital capacity; mMRC, modified Medical Research Council; OR, odds ratio.

increased with $\mathrm{BMI}<25 \mathrm{~kg} / \mathrm{m}^{2}$, with $\mathrm{mMRC} \geq 2$, and with any critical error (Figure 1).

\section{Discussion}

Of the 189 COPD patients enrolled, 50 (26.5\%) patients were frequent exacerbators. At least one critical inhaler error was observed in 81 (42.9\%) patients, although $95.2 \%$ received previous education for handling the inhaler. Lower BMI, higher $\mathrm{mMRC}$, and any critical error were risk factors for frequent exacerbations in COPD patients. The rate of exacerbation increased with BMI $<25.0 \mathrm{~kg} /$ $\mathrm{m}^{2}, \mathrm{mMRC} \geq 2$, and with any critical error. Critical errors were most commonly observed when using pMDI (57.1\%). Previous studies have also reported a high rate
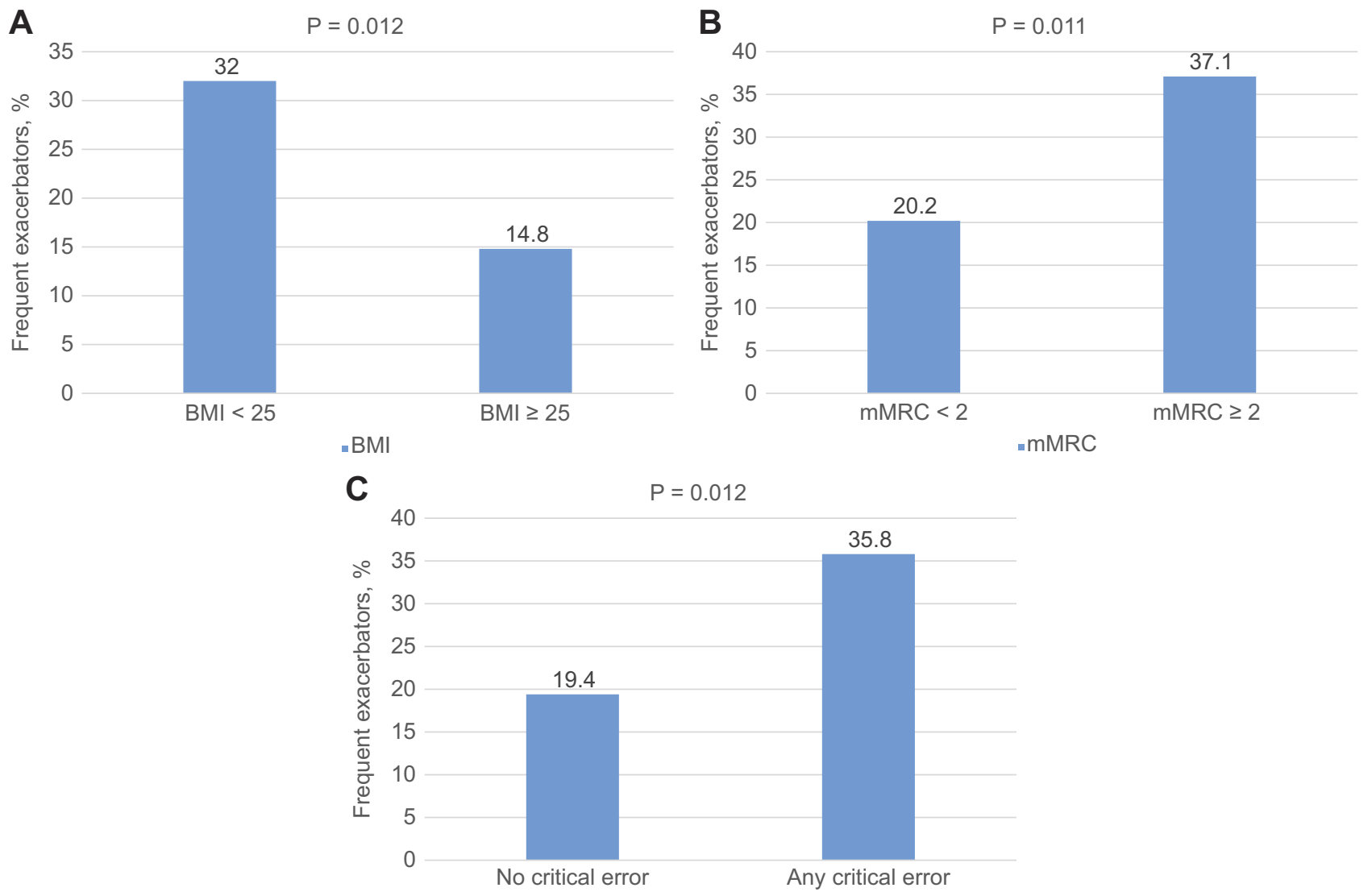

"Critical error

Figure I Rate of frequent exacerbators according to BMI, mMRC, and critical error.

Abbreviations: BMI, body mass index; GOLD, Global Initiative for Chronic Obstructive Lung Disease; mMRC, modified Medical Research Council. 
of inaccurate technique when using pMDI compared to other devices. 8,26 "Not breathing slowly and deeply" was the most common error in our study. pMDI requires a slow and deep inhalation, with an inspiratory flow rate of less than $60 \mathrm{~L} / \mathrm{min}$. Fast inhalation flow rates increase inertial impaction of aerosols in the oropharyngeal area and bifurcations of the airways, decreasing aerosol deposition to the lung. ${ }^{27}$ In a study that measured peak inhalation flows of COPD patients, approximately $60 \%$ of COPD patients inhaled more than $90 \mathrm{~L} / \mathrm{min}$ with the pMDI. ${ }^{28}$ "Lack of synchronization between actuation and inhalation" were also common errors. Poor actuation-inhalation coordination was observed in about $20-40 \%$ of patients with asthma and COPD. ${ }^{8,13,26}$

Critical errors were also commonly observed when using SMI (42.3\%) in this study. A recent large study demonstrated that Respimat ${ }^{\circledR}$ users had the highest rate of at least one critical error (46.9\%) among the inhaler devices. ${ }^{9}$ Inadvertent activation during routine dosing and lack of synchronization between hand and lung are common errors in other studies. ${ }^{9,29}$ Our study is consistent with these previous results. The most common errors in handling the SMI were "failure to twist the base a half turn," "failure to open the device correctly," and "lack of synchronization between actuation and inhalation" in this study.

Critical errors were observed in $39.1 \%$ of COPD patients when using DPI. Among the DPI devices, Diskus $^{\circledR}$ and Ellipta ${ }^{\circledR}$ users had fewer critical errors than users of Turbuhaler ${ }^{\circledR}$, Breezhaler ${ }^{\circledR}$, and Genuair ${ }^{\circledR}$. Dosepreparation errors (priming devices in the correct position, pressing the button correctly to pierce a capsule, and pushing the lever) were seen in $10-50 \%$ of patients using Turbuhaler $^{\circledR}(50.0 \%)$, Breezhaler ${ }^{\circledR}(22.4 \%)$, Diskus ${ }^{\circledR}$ (12.5\%), and Genuair ${ }^{\circledR}(21.4 \%)$. "Not inhaling forcefully or deeply" was seen in one fourth of DPI users.

Many previous studies have demonstrated an association between disease outcomes and inhaler errors in asthma patients. ${ }^{11,12,16,30,31}$ Studies demonstrating an association between disease outcomes and inhaler errors are rare in COPD patients. ${ }^{9,13}$ In one study, the Asthma Control Test (ACT) instrument was used to assess disease outcome in COPD patients. ${ }^{13}$ Molimard et al found an association between critical errors and severe COPD exacerbations in the prior 3 months. ${ }^{9}$ Press et al found that in-hospital education in inhaler technique was associated with fewer acute care events within 30 days after discharge. ${ }^{32}$ In our study, we found an association between critical errors and frequent COPD exacerbations over the prior 12 months. Any critical errors resulted in an OR of 2.020 of frequent exacerbations over the past year. According to the Global Initiative for Chronic Obstructive Lung Disease (GOLD) 2019 report, physicians should regularly assess inhaler technique and adherence. Poor inhaler technique must be considered a cause of poor treatment response. Therefore, it is important to assess inhaler technique and encourage patients to use their devices correctly. Those who cannot use their devices correctly require a different device. ${ }^{33}$

Exacerbation of COPD is defined as an acute worsening of respiratory symptoms that requires additional therapy. Some COPD patients experience frequent exacerbations and are now categorized as a distinct phenotype, the frequent exacerbators. These events are important and have a significant impact on COPD patients. These events negatively impact lung function, quality of life, activity, hospital admission, and mortality. ${ }^{3}$ At this time, the emphysematous phenotype, physician-diagnosed asthma, presence of gastroesophageal reflux disease, more severe airflow obstruction, use of inhaled corticosteroids, higher $\mathrm{mMRC}$, and higher BODE (BMI, degree of airflow obstruction, dyspnea, and exercise capacity) index are associated with the frequent exacerbator phenotype. ${ }^{34-37}$ Recently, Le Rouzic et al derived a score to predict the frequent exacerbator cluster, called the ESOD (Exacerbation history, chronic sputum production, GOLD stage of obstruction, and mMRC dyspnea stage). ${ }^{38}$ In our study, BMI $<25 \mathrm{~kg} / \mathrm{m}^{2}$, higher $\mathrm{mMRC}$, and any critical error were independent risk factors for frequent exacerbations. For the first time, our study demonstrated that critical error is an independent risk factor for frequent exacerbations in the prior year in patients treated for at least 1 year with a tested device.

There were some limitations to this study. First, as this study was conducted at a single center without randomization, selection bias could not be avoided. Our center is a regional center for respiratory disease in a university affiliated hospital setting, offering face-to-face inhaler education by an advanced practice nurse in routine clinical practice. However, the inhaler technique failure rate was relatively high despite thorough education. Therefore, patients in other hospital settings are thought to be much less accurate in using inhaler devices. These factors make it difficult to generalize our result to other patients. Second, assessing inhaler technique may be subjective in "inhale forcefully or deeply" when evaluating 
DPI devices and "synchronization between actuation and inhalation" and "inhale slowly and deeply" when evaluating SMI and pMDI devices. Devices measuring peak inspiratory flow are not available in our clinical practice settings. However, as mentioned above, the advanced practice nurse who assessed inhaler technique was previously educated and trained by COPD specialists and had 3 years of experience educating users on devices at the time of the study; therefore, the reliability of inhaler technique evaluation may be good. Third, other independent factors known to affect COPD exacerbation, such as comorbidities and the type of inhaler molecule, were not included. Fourth, the number of patients using a particular inhaler is very small. This is the case in DPI users because there are many types of DPI. Patients using more DPIs will be evaluated in the future studies. Fifth, as there is no consensus on standardized inhaler checklist, it is not clear whether our research checklist will work as a critical error in all COPD patients.

Our study also had several strengths. First, it is the first study in Korea to evaluate inhaler device technique and adherence in COPD patients; furthermore, we demonstrated an association between critical error and frequent exacerbations in COPD patients for the first time. Second, our research was conducted only on COPD patients. Asthma and COPD are different disease entity and studies of inhaler use technique and patient related outcomes should be checked separately from asthma and COPD. Our research has an advantage in that respect. Third, compared to a previous study in which inhalers were evaluated by many physicians, ${ }^{9}$ these evaluations were conducted by a single advanced practice nurse to eliminate interobserver variability. Fourth, we applied many outcome questionnaires including mMRC, CAT, MMSE, EQ-5D, PHQ-9, and FSI-10. No previous studies have compared a variety of outcome questionnaires between frequent exacerbators and infrequent exacerbators. Fifth, our study represents the actual use of inhalers at clinical sites. Although $95 \%$ of subjects had been educated previously for handling inhalers, a considerable number of patients made errors during inhaler use. In general clinics and general hospitals where training on inhaler use is difficult, patients are very likely to make more errors.

In conclusion, we found that any critical error, BMI $<25 \mathrm{~kg} / \mathrm{m}^{2}$ and higher $\mathrm{mMRC}$ are independent risk factors for frequent exacerbations in COPD patients. Careful monitoring and education on inhaler device use, particularly in frequent exacerbators, is an important component of COPD treatment.

\section{Ethical Statement}

This study was conducted in accordance with the Declaration of Helsinki. It was reviewed and approved by the institutional review board of our hospital (YUH IRB 2017-09-012). Written informed consent was obtained from all patients.

\section{Data Sharing Statement}

The datasets generated during the study are available from the corresponding author upon reasonable request.

\section{Acknowledgments}

We would like to express our appreciation to Mi Jeong Nam and Mi Suk Lee for gathering data for this study. Their devoted efforts were very helpful.

\section{Author Contributions}

All authors contributed to data analysis, drafting or revising the article, gave final approval of the version to be published, and agree to be accountable for all aspects of the work.

\section{Funding}

This work was supported by the Yeungnam University Research Fund in 2019.

\section{Disclosure}

The authors declare that they have no conflicts of interest.

\section{References}

1. Mathers CD, Loncar D. Projections of global mortality and burden of disease from 2002 to 2030. PLoS Med. 2006;3(11):e442.

2. GBD 2015 Chronic Respiratory Disease Collaborators. Global, regional, and national deaths, prevalence, disability-adjusted life years, and years lived with disability for chronic obstructive pulmonary disease and asthma, 1990-2015: a systematic analysis for the Global Burden of Disease Study 2015. Lancet Respir Med. 2017;5(9):691-706.

3. Wedzicha JA, Brill SE, Allinson JP, Donaldson GC. Mechanisms and impact of the frequent exacerbator phenotype in chronic obstructive pulmonary disease. BMC Med. 2013;11:181.

4. Lipson DA, Barnhart F, Brealey N, et al. Once-daily single-inhaler triple versus dual therapy in patients with COPD. $N$ Engl J Med. 2018;378(18):1671-1680.

5. Calverley PMA, Anzueto AR, Carter K, et al. Tiotropium and olodaterol in the prevention of chronic obstructive pulmonary disease exacerbations (DYNAGITO): a double-blind, randomised, parallel-group, active-controlled trial. Lancet Respir Med. 2018;6(5):337-344.

6. Donohue JF, Singh D, Munzu C, Kilbride S, Church A. Magnitude of umeclidinium/vilanterol lung function effect depends on monotherapy responses: results from two randomised controlled trials. Respir Med. 2016;112:65-74. 
7. Braido F, Baiardini I, Cazzola M, Brusselle G, Marugo F, Canonica GW. Long-acting bronchodilators improve health related quality of life in patients with COPD. Respir Med. 2013;107(10):1465-1480.

8. Pothirat C, Chaiwong W, Phetsuk N, Pisalthanapuna S, Chetsadaphan N, Choomuang W. Evaluating inhaler use technique in COPD patients. Int J Chron Obstruct Pulmon Dis. 2015;10:1291-1298.

9. Molimard M, Raherison C, Lignot S, et al. Chronic obstructive pulmonary disease exacerbation and inhaler device handling: real-life assessment of 2935 patients. Eur Respir J. 2017;49(2):1601794.

10. Lavorini F, Magnan A, Dubus JC, et al. Effect of incorrect use of dry powder inhalers on management of patients with asthma and COPD. Respir Med. 2008;102(4):593-604.

11. Westerik JA, Carter V, Chrystyn H, et al. Characteristics of patients making serious inhaler errors with a dry powder inhaler and association with asthma-related events in a primary care setting. J Asthma. 2016;53(3):321-329.

12. Capanoglu M, Dibek Misirlioglu E, Toyran M, Civelek E, Kocabas CN. Evaluation of inhaler technique, adherence to therapy and their effect on disease control among children with asthma using metered dose or dry powder inhalers. J Asthma. 2015;52(8):838-845.

13. Melani AS, Bonavia M, Cilenti V, et al. Inhaler mishandling remains common in real life and is associated with reduced disease control. Respir Med. 2011;105(6):930-938.

14. Loh CH, Peters SP, Lovings TM, Ohar JA. Suboptimal inspiratory flow rates are associated with chronic obstructive pulmonary disease and all-cause readmissions. Ann Am Thorac Soc. 2017;14(8):1305-1311.

15. Usmani OS, Lavorini F, Marshall J, et al. Critical inhaler errors in asthma and COPD: a systematic review of impact on health outcomes. Respir Res. 2018;19(1):10.

16. Baddar S, Jayakrishnan B, Al-Rawas OA. Asthma control: importance of compliance and inhaler technique assessments. J Asthma. 2014;51(4):429-434.

17. Kim V, Aaron SD. What is a COPD exacerbation? Current definitions, pitfalls, challenges and opportunities for improvement. Eur Respir J. 2018;52(5):1801261.

18. Hurst JR, Vestbo J, Anzueto A, et al. Susceptibility to exacerbation in chronic obstructive pulmonary disease. N Engl J Med. 2010;363 (12):1128-1138.

19. Bestall JC, Paul EA, Garrod R, Garnham R, Jones PW, Wedzicha JA. Usefulness of the Medical Research Council (MRC) dyspnoea scale as a measure of disability in patients with chronic obstructive pulmonary disease. Thorax. 1999;54(7):581-586.

20. Jones PW, Harding G, Berry P, Wiklund I, Chen WH, Kline Leidy N. Development and first validation of the COPD Assessment Test. Eur Respir J. 2009;34(3):648-654.

21. Folstein MF, Folstein SE, McHugh PR. "Mini-mental state". A practical method for grading the cognitive state of patients for the clinician. J Psychiatr Res. 1975;12(3):189-198.

22. EuroQol Group. EuroQol-a new facility for the measurement of health-related quality of life. Health Policy. 1990;16(3):199-208.

23. Spitzer RL, Kroenke K, Williams JB. Validation and utility of a self-report version of PRIME-MD: the PHQ primary care study. Primary Care Evaluation of Mental Disorders. Patient Health Questionnaire. JAMA. 1999;282(18):1737-1744.
24. Perpina Tordera M, Viejo JL, Sanchis J, et al. Assessment of patient satisfaction and preferences with inhalers in asthma with the FSI-10 Questionnaire. Arch Bronconeumol. 2008;44(7):346-352.

25. Faul F, Erdfelder E, Buchner A, Lang AG. Statistical power analyses using $G^{*}$ Power 3.1: tests for correlation and regression analyses. Behav Res Methods. 2009;41(4):1149-1160.

26. Lee SM, Chang YS, Kim CW, et al. Skills in handling turbuhaler, diskus, and pressurized metered-dose inhaler in korean asthmatic patients. Allergy Asthma Immunol Res. 2011;3(1):46-52.

27. Capstick TG, Clifton IJ. Inhaler technique and training in people with chronic obstructive pulmonary disease and asthma. Expert Rev Respir Med. 2012;6(1):91-101; quiz 102-103.

28. Al-Showair RA, Tarsin WY, Assi KH, Pearson SB, Chrystyn H. Can all patients with COPD use the correct inhalation flow with all inhalers and does training help? Respir Med. 2007;101(11):23 95-2401.

29. Ding B, Siddiqui S, DePietro M, Petersson G, Martin UJ. Inhaler usability of a pressurized metered dose inhaler and a soft mist inhaler in patients with COPD: a simulated-use study. Chron Respir Dis. 2019;16:1479972318787914.

30. Al-Jahdali H, Ahmed A, Al-Harbi A, et al. Improper inhaler technique is associated with poor asthma control and frequent emergency department visits. Allergy Asthma Clin Immunol. 2013;9(1):8.

31. Levy ML, Hardwell A, McKnight E, Holmes J. Asthma patients' inability to use a pressurised metered-dose inhaler (pMDI) correctly correlates with poor asthma control as defined by the global initiative for asthma (GINA) strategy: a retrospective analysis. Primary Care Respir j. 2013;22(4):406-411.

32. Press VG, Arora VM, Trela KC, et al. Effectiveness of interventions to teach metered-dose and diskus inhaler techniques. a randomized trial. Ann Am Thorac Soc. 2016;13(6):816-824.

33. Singh D, Agusti A, Anzueto A, et al. Global strategy for the diagnosis, management, and prevention of chronic obstructive lung disease: the GOLD science committee report 2019. Eur Respir J. 2019;53(5):1900164.

34. Wan ES, DeMeo DL, Hersh CP, et al. Clinical predictors of frequent exacerbations in subjects with severe chronic obstructive pulmonary disease (COPD). Respir Med. 2011;105(4):588-594.

35. Tomioka R, Kawayama T, Suetomo M, et al. "Frequent exacerbator" is a phenotype of poor prognosis in Japanese patients with chronic obstructive pulmonary disease. Int J Chron Obstruct Pulmon Dis. 2016;11:207-216.

36. Oh YM, Sheen SS, Park JH, et al. Emphysematous phenotype is an independent predictor for frequent exacerbation of COPD. Int $j$ Tuberculosis Lung Dis. 2014;18(12):1407-1414.

37. Capozzolo A, Carratu P, Dragonieri S, et al. Clinical and functional lung parameters associated with frequent exacerbator phenotype in subjects with severe COPD. Respir Care. 2017;62 (5):572-578

38. Le Rouzic O, Roche $\mathrm{N}$, Cortot $\mathrm{AB}$, et al. Defining the "Frequent exacerbator" phenotype in COPD: a hypothesis-free approach. Chest. 2018;153(5):1106-1115.

\section{Publish your work in this journal}

The International Journal of COPD is an international, peer-reviewed journal of therapeutics and pharmacology focusing on concise rapid reporting of clinical studies and reviews in COPD. Special focus is given to the pathophysiological processes underlying the disease, intervention programs, patient focused education, and self management protocols. This journal is indexed on PubMed Central, MedLine and CAS. The manuscript management system is completely online and includes a very quick and fair peer-review system, which is all easy to use. Visit http://www.dovepress.com/testimonials.php to read real quotes from published authors. 